\title{
ESEM - the ultimate in-situ observation tool at high and low temperatures
}

\author{
M. Schmied, H. Schroettner, J. Wagner
}

Graz University of Technology, Research Institute for Electron Microscopy, Steyrergasse 17, 8010 Graz, Austria

The environmental scanning electron microscope (ESEM) facilitates besides the excellent imaging capabilities of e.g. insulating materials, the unique possibility of an in-situ observation in the microand submicrometer regime. By using heating stages up to $1500^{\circ} \mathrm{C}$, different processes, such melting behaviour or phase transitions at very high magnification can be investigated. On the other hand cooling stages enable the investigation of wet samples and for e.g. the swelling behaviour of cellulose fibres.

Heating stage experiments were performed with a $\mathrm{Cu}-\mathrm{Zr}$ alloy $(5 \% \mathrm{wt} \mathrm{Zr})$ at temperatures up to $1400^{\circ} \mathrm{C}$. Water vapour at a pressure of $400 \mathrm{~Pa}$ was used as the imaging gas. Additional $\mathrm{Al}_{2} \mathrm{O}_{3}$ rods were added on the top of the piece of alloy. The alloy was heated up in $200^{\circ} \mathrm{C}$ steps with a ramp of $30 \%$ min. As shown in Fig.1a, melting spheres were formed on these $\mathrm{Al}_{2} \mathrm{O}_{3}$ rods at heating stage temperatures of $1400^{\circ} \mathrm{C}$. After the formation of the melting spheres the cooling down procedure was performed with a ramp of again $30^{\circ} \mathrm{C} / \mathrm{min}$, whilst the formation of crystals and precipitates could be observed at high magnification as shown in Fig.1b. The precipitates were mainly formed at the crystal interfaces. In Fig.1c also growth zones on the surface of the crystals could be observed, whereas the images were indicating that even twin boundaries were formed.

Based on DTA (differential thermoanalysis) data of a ceramic green-body, which shows the phase transitions within the sintering process at certain temperatures $\left(\sim 900^{\circ} \mathrm{C}\right.$ and $\left.\sim 1200^{\circ} \mathrm{C}\right)$, the heating stage experiment was performed with the same temperature profile. Water vapour was used as the imaging gas at the fixed value of $400 \mathrm{~Pa}$. During the heating stage experiment (total $9 \mathrm{hrs}$ ) the sample and heating shield bias was adjusted to optimum contrast and brightness. The phase transition at $900^{\circ} \mathrm{C}$ could not be detected, whereas at $1200^{\circ} \mathrm{C}$ and above the morphological changes nicely correspond to the stated phase transitions in the DTA results (Fig.2). Crystal growth could be observed during the cooling down procedure, where two separate forms of crystallites with different size distributions were formed. The total sintering shrinkage was determined to be approximately $25 \%$ (vol.), which also corresponds to the conventional sintering data.

The heating experiment showed clearly the new capabilities of this in-situ technique, where processes can be observed at very high magnifications, giving detailed information of process steps. Furthermore the composition of the formed spherical particles could be determined by using the FIB producing TEM slices of the desired areas.

References

[1] I.Belenli, M. Ebrahimi and Y. S. Hascicek, Physica C: Superconductivity

Volume 247 Issues 3-4 (1 June 1995) 371-375

[2] V.A. Maroni, Physica C 313 (1999) 169-174

[3] D. Oquab, Scripta Mater. 44(2001) 2741-2746

[4] B.A. Wilson, Journal o Mater.Science 34 (1999) 247-250 

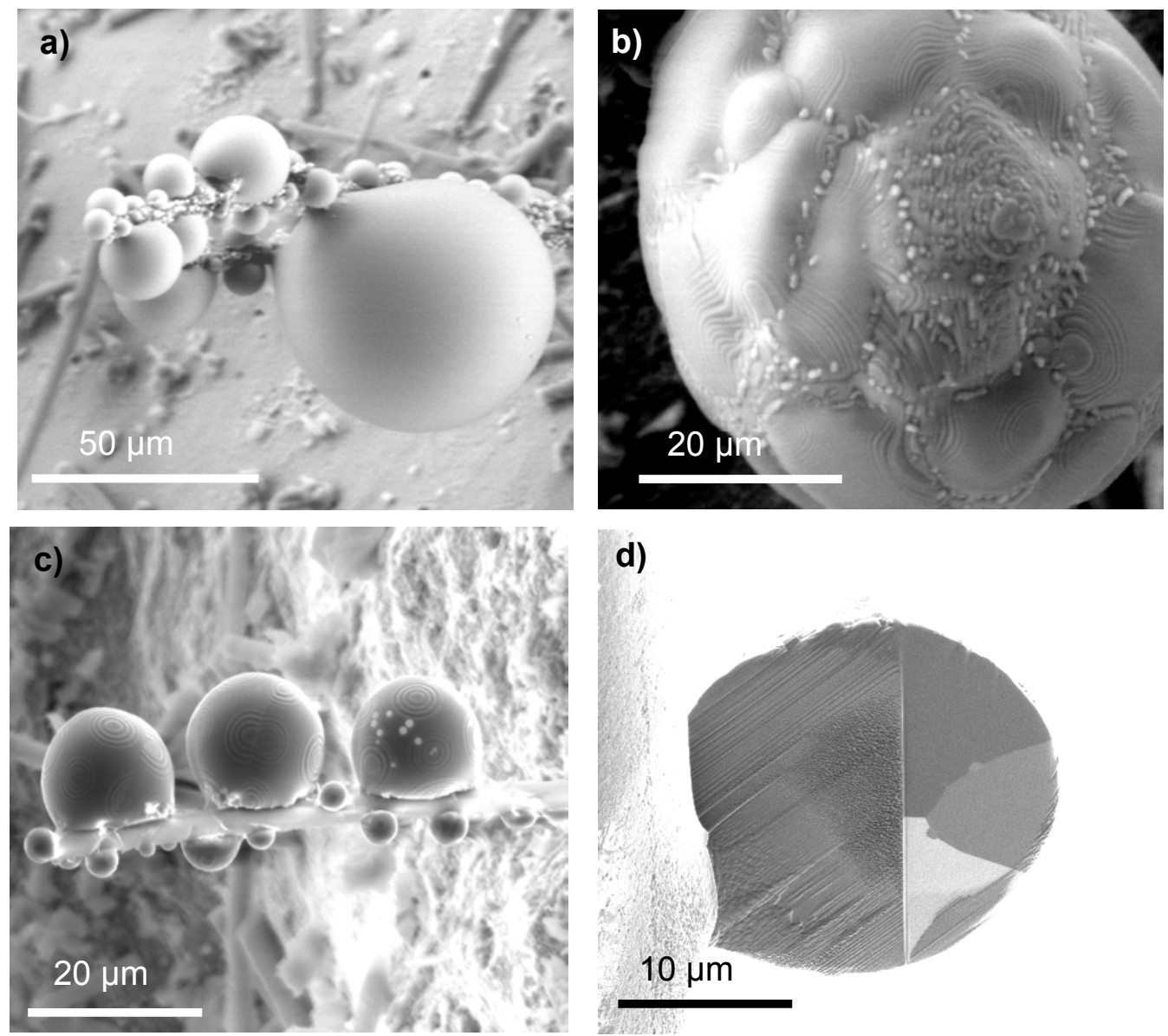

Fig.1: a) melting phase on a $\mathrm{Al}_{2} \mathrm{O}_{3}$ rod recorded at $1400^{\circ} \mathrm{C}$; b) in-situ observation of grain and precipitates formation during the cooling down procedure (at $\left.820^{\circ} \mathrm{C}\right)$; c) spherical particles showing growth zones and twin boundaries; d) semi-sphere mounted on a TEM grid and showing channelling contrast after ion-beam milling
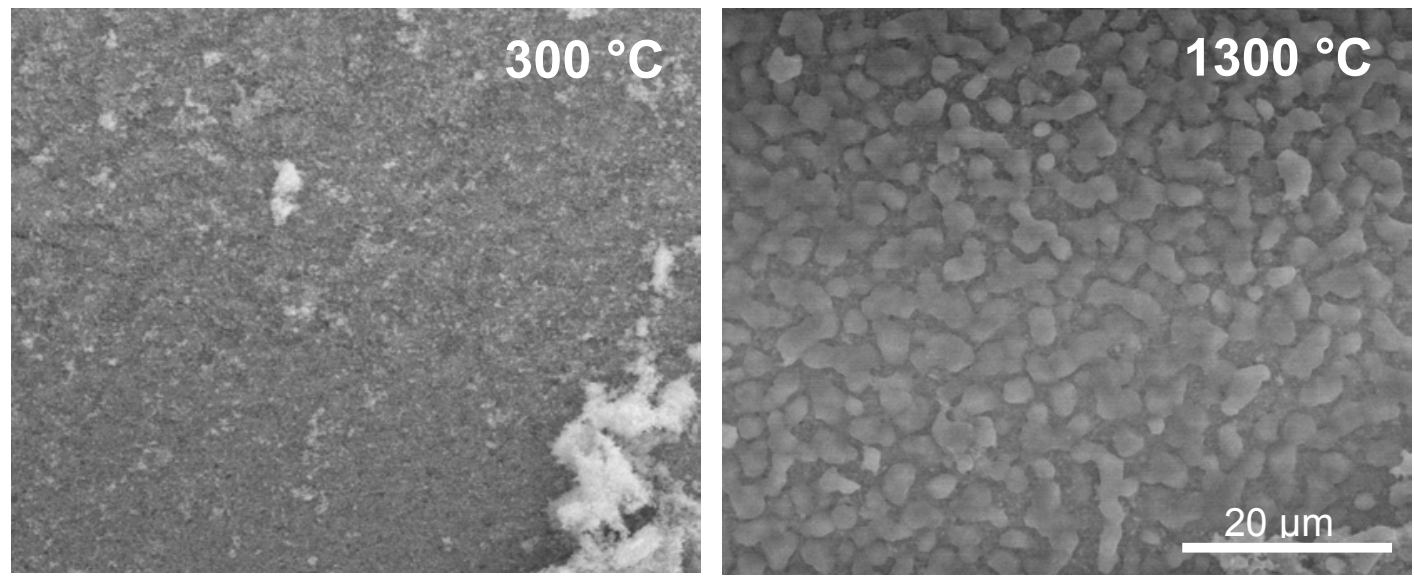

Fig.2: Phase transitions during the sintering process at the surface of the ceramic green-body 